\title{
Competing or Accommodating? An Empirical Test of Chinese Conflict Management Styles
}

\author{
Zhenzhong Ma \\ University of Windsor \\ E-Mail:maz@uwindsor.ca
}

\begin{abstract}
Researchers have been investigating the distinctness of Chinese conflict management styles, yet have to provide solid evidence for such differences. This study provides support for this issue by using multiple negotiation simulations to illustrate how Chinese people conflicts and how their preferred conflict management styles affect their negotiation behaviour and outcomes in business negotiation. Results show that compromising and competing, instead of accommodating, are two preferred methods for conflict resolution in China. Managerial implications are then discussed, which concludes this paper.
\end{abstract}

Keyword: Conflict Management Style, China, Compromising, Competing

\section{INTRODUCTION}

Conflict management has developed into a major sub-field of organizational behavior within a short time period (Kozan, 1997). This trend underlines the greater acceptance of conflict as an organizational phenomenon, and as a result, concerns over its management. Researchers have also witnessed an increased interest in management in a cross-cultural context (cf. Adler \& Graham, 1989). Yet, the existing literature on crosscultural research is not as rich in conflict management as in other fields (Kiggundu, Jorgensen, \& Hafsi, 1983; Kozan, 1997). Because both the comparative aspect and the interactive aspect of conflict management across cultures are of paramount importance to the working of an increasingly globalized work environment, a comprehensive examination of conflict management across cultures is in great need. 
A number of relevant studies have been conducted during the past decade, mostly by experimental social psychologists (e.g. Jehn \& Weldon, 1992; Kozan, 1997; Sorenson, Morse, \& Savage, 1999). In spite that these studies have produced an impressive literature on the best methods to manage conflict, there are deficiencies, and these deficiencies have impeded the further development of the research in cross-cultural conflict management.

The first deficiency of existing research is lacking of integrative international studies because of the relatively young field of conflict management and international organizational behavior (Kozan, 1997), and because of the lack of culture-free measures of conflict management styles (Weldon \& Jehn, 1995). Many studies about conflict management investigate the single culture case with most samples from Western cultures, and few studies have gone beyond that to explore the conflict styles in non-Western cultures (see Weldon \& Jehn, 1995 for a review). Because conflict is culturally defined and regulated event (Hocker \& Wilmot, 1991), conflict management should differ across cultures. To provide more useful information on conflict management for the globalized working environment, international studies with samples from non-Western cultures are required. In addition to the practical importance of understanding conflict management in the global marketplace, studying conflict in varied cultural contexts can challenge and refine the present understanding of conflict management. Incorporating ideas and practices of other cultures can help develop more enduring, elegant, and universal theories (van de Vijver \& Leung, 1997; Tjosvold, Leung, \& Jonson, 2000).

Among those studies that have investigated conflict manage styles across cultures, only inconsistent results are obtained, accompanied by weak support for cultural specific methods (see Weldon \& Jehn, 1995 for a review). The shortcoming of this line of research comes from the fact that all the researchers adopt the single case method, i.e., collecting data from only one instance of situation. In her assessment of Thomas-Kilmann Conflict Mode Instrument, Womack (1988) pointed out correctly that since both personality and situational factors influence the choices of conflict management styles correlations between actual behaviors and measured scores in a single situation might not be high. Along this line, she called for more integrative studies to examine an individual's preferred styles across multiple situations, but it is not evident from the literature on conflict management that any one has taken up the challenge. No study assessing such a relationship exists in the literature. 
A second deficiency of existing literature on cross-cultural conflict management is lack of actionable knowledge. As is well known, a key part of the academic research requires that science-based knowledge be relevant, responsible, and make a valuable contribution to society and its institutions. However, much of current knowledge on conflict management remains on the academic side of chasm, failing to answer such question as "so what?' For instance, the majority of the international studies on conflict management have painstakingly delineated conflict style differences across different cultures and have made great effort explaining such differences, few, if any, have tried to investigate whether such differences make some styles more effective in resolving conflicts in one culture than in another (Jehn \& Weldon, 1992; Trubisky, Ting-Toomey, \& Lin, 1991; Weldon \& Jehn, 1995).

In response to these limitations, this study explicitly investigated Chinese preferred conflict management styles. Data were generated using 3 different contextually rich simulations of business negotiation, a popular format of conflict resolution, to explore the general conflict styles across situations and to answer the question what might be the most effective methods to resolve conflicts in China. I chose China because China is a powerful test of the universalistic aspiration of the Western theory of conflict management, in particular of its utility in understanding the conditions and dynamics through which conflict is resolved. Moreover, Chinese culture is a collectivist culture and Chinese people are expected to be particularly wary of open confrontations in order to maintain good relationships and therefore are more likely to accommodate the other's needs to keep peace (Hofstede, 1980). Although there is no lack of anecdotal and descriptive evidence confirming the differences between the East and the West and the difficulties that Westerners have in negotiating to resolve conflicts with the Chinese, little research exists documenting the actual process of conflict management in China. I believe that before Westerners can begin to decipher their own patterns of interaction with the Chinese, they need more reliable data on how the Chinese handle these issues among themselves. This study took the step of testing a Western conflict management model in a Chinese context and exploring the differences of Chinese conflict styles.

The present study is thus distinctive in that (1) it strives to assess Chinese conflict management styles across 3 different situations, and further (2) it explores the effects of different conflict styles on the process and outcomes of conflict resolution in China, which thus provides clear guidance on what is the most effective method in resolving conflicts in this country. 


\section{CONFLICT MANAGEMENT STYLES}

Researchers have studied the best ways to manage conflict, resulting in an impressive literature (cf. Thompson, 1990; van de Vliert, 1997; Wall \& Blum, 1991). The dominant conflict management model in this literature is dual-concern model. Originated from the work of Blake and Mouton (1964), the dual-concern model has several variations, all of which assume that individuals choose different modes, strategies, or styles for handling conflict based on some variations of two primary concerns/interests"concern for self" and "concern for other".

Perhaps the best known and the most accepted dual-concern model is that of Thomas (1976) which identifies five different conflict-handling styles based on two dimensions: assertiveness and cooperativeness. Assertiveness measures the extent to which an individual attempts to satisfy his/her own concerns, and cooperativeness assesses the extent to which an individual attempts to satisfy the other person's concerns. As shown in Figure 1, these two dimensions yield five conflict styles: competing (high concern for self, low concern for others), collaborating (high concern for self and others), compromising (moderate concern for self and for others), accommodating (low concern for self and high concern for others), and avoiding (low concern for self and low concern for others). These five styles reflect an individual's behavioral intentions when facing conflict situations (Womack, 1988). Subsequent studies suggest that the interrelationships among the constructs are consistent with those depicted in the model (van de Vliert \& Kabanoff, 1990; van de Vliert \& Euwema, 1994) and that the two dimensions provide the base for choice of conflict modes (Sorenson, Morse, \& Savage, 1999).

Because conflict is a culturally defined event, conflict management styles in different cultures are expected to be differing from one another. For example, in a collectivistic society, social relationships and social harmony are important concerns (Triandis, 1995). Harmony often takes precedence over task accomplishment and personal desires. Individual effort and achievement are expected to contribute to the collective good (Hofstede, 1980). In contrast, in an individualistic society, people value autonomy, assertiveness, competition, and individual achievement. Consequently, they strive for personal satisfaction and achievement even at the expense of social relationships (Triandis, 1995). Therefore, it can be expected that individualism should produce direct, task-oriented conflict management styles reflecting great concern for self and little concern for others, and collectivism should motivate avoiding, indirect styles that reflect concerns for others. Because China is a highly collectivist country, it is 
expected that Chinese people will use more non-confrontational styles_accommodating, compromising, and avoiding styles in conflicting situations such as business negotiation, where attempts are made to avoid direct confrontation and to maintain the harmony.

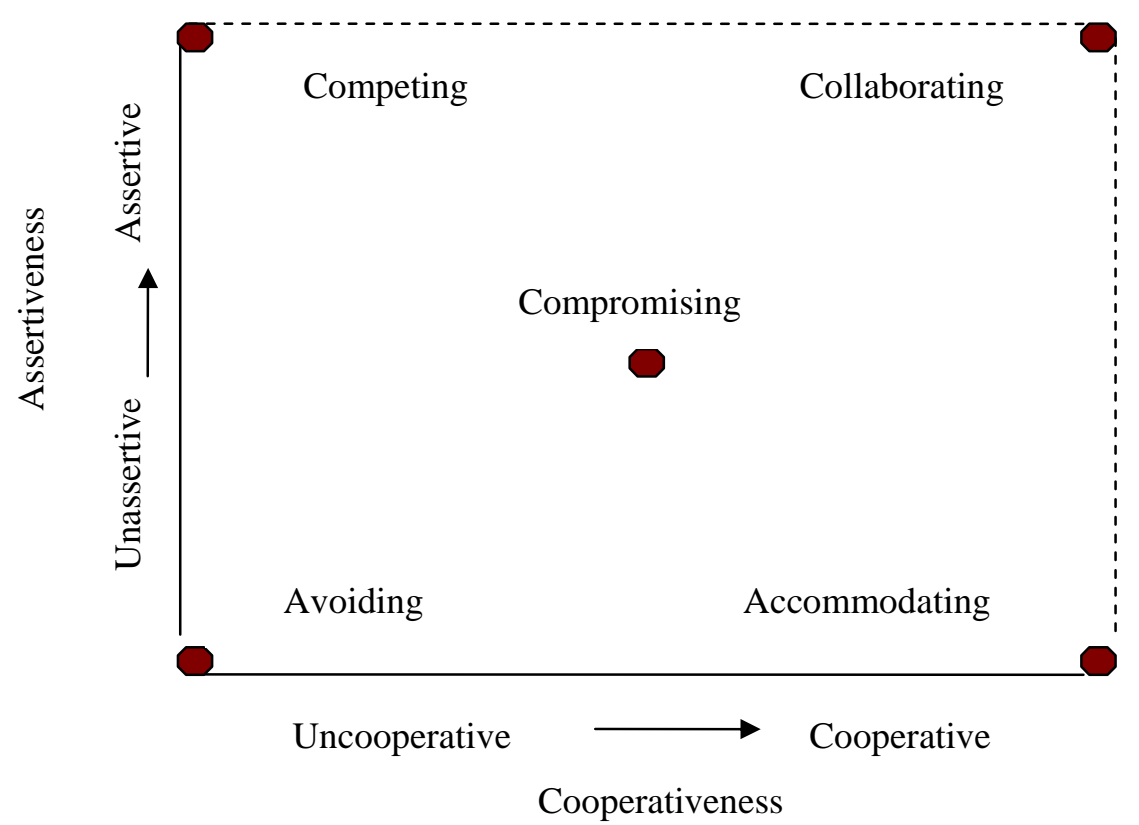

Figure 1: The Thomas Model of Conflict-handling Styles Adapted from Thomas (1976)

\section{CONFLICT MANAGEMENT STYLES AND NEGOTIATION}

Negotiation is a frequently invoked mechanism for resolving the conflicts between individuals or the representatives of groups. To certain extent negotiation behaviors can be said to be predicated upon conflict management styles (Kirkbride, Tang, \& Westwood, 1991). Others equal, different conflict styles are expected to translate into different behaviors in the process of negotiation, which further generates different outcomes. However, surprisingly few studies have attempted to examine this relationship (Volkema \& Bergmann, 1995), resulting in an unresolved question: Do conflict styles predict actual behaviors during the process of conflict resolution such as negotiation? Some scholars suggested a contingency approach to handling conflict, meaning that the appropriateness of using a particular style depends on the conflict situation, but the contingency approach fails to acknowledge that individuals may not be flexible and knowledgeable enough to use whichever style is best for a particular situation.

In this study, I will use buyer-seller negotiation tasks with integrative potentials to 
examine the influence of conflict management styles on negotiating behaviors and on subsequent outcomes. I predict that different conflict management styles have implications for the manner in which the negotiation process is tackled, leading to different outcomes. These styles may also have direct effects on negotiation outcomes without operating through the intervening medium of negotiation behaviors.

Negotiation Process Negotiation process is the dynamic interaction between negotiators by which the two parties exchange goods or services and attempt to agree upon an exchange rate by resolving incompatible goals (Carnevale \& Pruitt, 1992; Wall, 1985; Wall \& Blum, 1991). Among other factors, the level of assertiveness, integrativeness, and first offer have been found to play important roles during negotiations (Barry \& Friedman, 1998; Lewicki \& Litterer, 1985; Greenhalgh, Nelsin, \& Gilkey, 1985). Their relationship with conflict management styles and with the negotiation outcomes will be examined in this study.

Assertiveness involves a freer exchange of information and persuasion and more active involvement in pushing negotiation forward. As one of the central dimensions of negotiation behavior, the level of assertiveness during negotiation has been examined and proved to be one important factor that affects negotiation outcomes (e.g., Greenhalgh, Nelsin, and Gilkey 1985; Ma, 2006; Ma, Wang, Jaeger, Anderson, \& Wang, 2000; Mnookin, Peppet, \& Tulumello, 1996). Similarly, the level of integrativeness or "winwin" intent of negotiation behavior has also been closely related to negotiation outcomes (Lewicki \& Litterer, 1985; Lewicki, Litterer, Minton, \& Saunders, 1994). In this study, their relationship with conflict management styles will be examined.

The effect of the level of first offer will also be investigated in this study. Depending on the culture context, different people from different cultural background could have very different first offer, from the extreme ones to the very moderate ones. In any negotiation, the decision to put the first offer on the table is a double-edged sword (Barry \& Friedman, 1998). To the offerer's potential disadvantage, an initial offer conveys information about aspirations and utilities (Rubin \& Brown, 1975). Depending on the underlying structure of reservation prices, this information may reduce the range of potential agreements, to the disadvantage of the offerer. On the other hand, an opening offer may lead the opponent to perceive that settlements will favor the party making the first offer. This is more likely to happen when the first offer is an extreme one (Siegel \& Fouraker, 1960). For example, a seller who initially demands a high price may induce the buyer to believe that the range of potential agreements is closer to the seller's reservation 
price than originally thought. Moreover, extreme initial offers can signal that the party making the offer is hard bargainer who will not be induced to retreat (Lewicki et al., 1994). When this occurs, the recipient of such an offer may moderate his or her negotiation objectives and be more inclined to offer concessions. Therefore, bargainers who make the first move may be better off starting with a relatively extreme offer, though there are limits to the effectiveness of extreme offers (e.g., offers so extreme that they discredit the bargainer who made the offer or reduce hope on the other side to the point of withdrawal) (Barry \& Friedman, 1998).

Negotiation Outcome In the present study, two key outcome constructs will be considered: (1) negotiator's individual profit, and (2) negotiator's satisfaction. The inclusion of negotiator's individual profit reflects the main objective of most negotiation studies. The ultimate goal of negotiation research is to find approaches that could be used to improve negotiator's individual profit and to look for those factors-no matter how they are categorized-that influence individual profit. To explore the effects of different conflict management styles, individual profit will be examined in this study as one criterion variable.

Satisfaction as one affective outcome has been linked to functional behaviors in a variety of settings (Churchill, Walker, \& Ford, 1990), and is considered a critical outcome measure of exchange relationships like business negotiation (Ruekert \& Churchill, 1984). This is especially true when integrative negotiations are crucial and long-term relationships become more important than one-shot negotiation successes. Satisfaction, including self's satisfaction or the other's satisfaction, is the factor that can increase the possibility of an integrative or "win-win" solution and that helps maintain the positive relationships. Thus, it is essential to include satisfaction as a primary negotiation outcome.

The research issue that will be examined here is the link between different conflict management styles and the negotiation process and outcomes. More specifically, the question to be answered in this study is, "What kind of conflict styles will affect a negotiator's behavior and the corresponding outcomes in China? And which style is the most effective one?” The relationships between conflict styles, negotiation process, and negotiation outcomes will be investigated under 3 different simulations. These simulations have different potential for integrative solutions, ranging from the least integrative to the most integrative. Finally, satisfaction with both negotiation outcomes and negotiation process are measured as the negotiator's general evaluation of negotiation results. 


\section{METHODS}

This study used 3 different negotiation simulations to investigate the nature of conflict styles in China and to explore the effects of different styles on negotiation process and outcomes. The conflict styles were measured with the Thomas-Kilmann Conflict Mode Instrument (1974), and negotiation process and outcomes were assessed by a variety of methods. The original questionnaires and negotiation cases used were developed in English. Translation and back-translation procedures were followed to ensure the equivalence for all the questions and the cases used in the simulations (Brislin, 1986).

\section{Simulations}

Because conflict management styles is a generalized, enduring tendency for people to respond to conflicts in a similar manner across situations and times (Thomas, 1976; Volkema \& Bergmann, 1995; Womack, 1988), the appropriate way to study the impact of conflict styles on negotiations is to gather data from many different negotiation situations and to investigate their effects on the average negotiation outcomes across situations (Lewicki et al., 1994). Such a method allows measurements and other errors to cancel each other out across negotiation situations and increases the probability that true effects will be found.

Following this logic, we used 3 diverse negotiation simulations in this study: the Used Car case, the Knight/Excalibur case, and the Best Book/Paige Turner case, all of which are common exercises in many negotiation textbooks (cf. Lewicki et al., 1994). We chose these 3 cases as they represent increasing level of complexity and different integrative potentials. The Used Car case is the simplest one wherein the seller and the buyer try to negotiate on the price of one second-handed car. This case is purely distributive, with price as the only issue for both sides. In the Best Book/Paige Turner case, which is the most complex, there are 8 issues to be negotiated, including royalties, signing bonus, duration of the contract, and other conditions. Representatives of the publisher and the author have to come to an agreement on all 8 issues. To assess individual negotiator' profits, each subject receives a profit table indicating his or her profit points earned on each issue of a set of possible agreements.

The Knight/Excalibur case falls in the middle, simpler than the Best Book case, but more complex than the Used Car case. In this simulation, representatives of two companies come to negotiate on the price of one special type of piston, but the buyer could possibly give the seller a free ride ad so that the seller might receive orders from 
the government in the future, if the seller would lower the price. The Knight/Excalibur case has much simpler structure than that of the Best Book but its integrative potential is easier to perceive.

The manipulation check showed that subjects' perceptions of the integrative potential for each simulation were significantly different from one another: The average perceptions of the integrative potentials for the Used Car case, the Knight/Excalibur case, and the Best Book case were 3.81, 5.19, and 4.37 respectively, on 7-point Likert scale (F $=27.72, \mathrm{p}<.001$, one-way ANOVA test), with the Used Car the most distributive case, and the Knight/Excalibur the most integrative case.

\section{Subjects}

Two hundred Chinese students participated in the negotiation simulations in this study, which is part of a larger international project. The students were undergraduates in business or related fields from the business school of a premier university in Beijing, China. Most subjects were between 20 and 26 years old, and 70\% were male. All subjects participated in order to fulfill course requirements, and all subjects were randomly assigned to pairs, which in turn were randomly assigned to different roles for either the buyer or the seller in each simulation.

\section{Procedures}

Before the simulations, subjects were told that they would be participating in 3 business negotiation simulations in which they would play the roles they were randomly assigned to. They were instructed to be as creative as they wanted to be, and they were also ensured that this study was only for academic purposes and confidentiality was guaranteed.

For each simulation, the subjects were randomly paired-off into buyer-seller dyads and assigned to different rooms for negotiation, where every subject read a common background statement and a separate confidential information sheet for the role he or she was assigned to. The sheet outlined the issues from the point of view of the constituency he or she represented, giving the subjects a general idea of the importance of the issues to be negotiated, and a detailed idea of the relative importance of the bargaining issues, if more than one issue had to be negotiated. Each student was given the Thomas-Kilmann Conflict Mode Instrument (MODE) to complete before starting the negotiations. The relationships being investigated had not been discussed with the subjects, and there were 
no inter-subject discussion of the negotiation until the study had been completed.

Before starting the actual negotiation, all the subjects spent 30 minutes reading and preparing for each negotiation, and then they filled out a pre-negotiation questionnaire (see Measures section below). They had 30 minutes to negotiate an agreement. A postnegotiation questionnaire was given to student to fill out (see Measures section below) after they completed the negotiation or when the time was up. The same procedure was followed for the other simulations, with debriefing and questions answered when all simulations had been completed. All subjects reached agreements in at least two simulations, and therefore all were included in the analysis.

\section{Measures}

Conflict Styles The Thomas-Kilmann Conflict Mode Instrument (MODE) was used to measure conflict management styles. The MODE is designed to gauge an individual's behavioral intention in conflict situations, and it has been the most widely accepted questionnaire of its type in both research and training. Comparing to other scales derived from dual-concern model, the MODE is also relatively uncontaminated by social desirability effects (Womack, 1988). The MODE has been used in numerous studies on conflict management in both single culture research and cross-cultural studies (Calhoun \& Smith, 1999; Weldon \& Jehn, 1995), and scholars have argued that it can be used cross-culturally (e.g., Kirkbride, Tang, \& Westwood, 1991).

The MODE consists of 30 pairs of statements describing different behavioral response to conflict situation. Typical items contrast responses such as "I try to avoid creating unpleasantness for myself" and "I try to win my position" or "I try to find a compromise solution" and "I sometimes sacrifice my own wishes for the wishes of the other person". Respondents are forced to choose the response most typical of their own behavioral intentions from each pair of statements and the resulting pattern of responses generates individual scores for each of the five conflict styles.

Cronbach (1951) alpha coefficients were calculated for the MODE in this study. Coefficients for the five styles ranged from .52 to .71, with a mean of .58, which are comparable to prior results (for a review, see Womack, 1988). It is worthwhile to point out that the Cronbach alpha coefficients for the MODE are underestimated due to the unique design of the MODE. Because the MODE is designed to force people to choose between a pair of statements, or between the conflict-handling modes, each item should load on two different styles. As a result, even if the measure were perfect, each scale 
score could at best account for only half the variance in any given item. In other words, even with a perfectly reliable and valid MODE, each item could only at most have a correlation of about .7 with its scale score, so that its R-square value would be .5 in explaining variance in the scale (K. Thomas, personal communications, Dec. 21, 2003).

Negotiation Process Negotiator's level of first offer was measured in pre-negotiation questionnaire by asking subjects to write down what their first offer would be for the current negotiation. In post-negotiation questionnaire, each subject answered the question regarding the level of their integrativeness and the level of their opponents' assertiveness. The level of integrativeness was measured on a 7-point Likert scale by asking subjects to indicate to what extent they were trying to reach integrative or distributive solutions during the negotiation (1-very distributive, 7-very integrative). To reduce the common method errors, their opponents' assessment was used to measure individual negotiators' level of assertiveness on a 7-point Likert scale, with 1 representing "not at all assertive" and 7 representing "very assertive”.

Negotiation Outcome Also collected in post-negotiation questionnaire were negotiator's individual profit, satisfaction with negotiation. Individual profit was measured as the final achieved profit. The measure for negotiator's satisfaction consisted of two items: negotiator's satisfaction with process and negotiator's satisfaction with outcome, both of which were measured by asking subjects to indicate on a scale from 1 (the most dissatisfied) to 7 (the most satisfied) how satisfied they were with the negotiation process or with the negotiated outcome. The satisfaction scale had a Cronbach alpha of .87.

As suggested by van de Vijver and Leung (1997) for conducting international research, standardization was used in this study to eliminate unwanted inter-group differences such as those due to response sets and to reduce the influence of measure units. The level of first offer and individual profit were standardized for sellers and for buyers respectively, and then the standardized scores for the buyers were reversed so that the higher score represented better deal for both the buyers and the sellers.

To test the true effects of conflict styles on negotiation process and outcomes, all the behavioral and outcome variables were averaged across simulations before the analysis, including standardized level of first offer, the level of assertiveness assessed by opponents, the level of integrativeness during negotiation, standardized individual profits, and satisfaction with negotiation. 


\section{RESULTS}

Table 1 reports means, standard deviations, and correlations among gender, conflict styles, negotiation process, and negotiation outcomes. In general, the bivariate correlations reflect expected relations and provide confidence that the measures functioned properly for the effects tested in this study.

From the mean scores of conflict styles we can see a clear preference for compromising style, which is significantly different from its closest rival -avoiding $(\mathrm{t}=$ 2.823, $\mathrm{p}<.005$ ), and a secondary preference for avoiding, followed by competing and collaborating, with accommodating as the least preferred style. This result reveals, on the one hand, that the Chinese tend to approach the conflicts in a non-assertive style, i.e., compromising or avoiding, which is the first choice and the second choice for conflict resolution in China. On the other hand, competing, instead of accommodating, is the third choice when handling conflicts, which suggests that the Chinese may not sacrifice themselves only for the sake of relationship building, as many have expected. Such a preference structure support our prediction that collectivist Chinese use more indirect styles, such as compromising or avoiding, to resolve conflict, though competing is also found, not without surprise, very important for conflict handling in China.

Figure 2 presents the hierarchical regression analysis results. In order to assess the independent and incremental effects of conflict styles on the two sets of dependent variables-negotiation process and outcomes, and for the exploratory nature of this study, the hierarchical regression analysis is appropriate. In the regression analysis, gender was always entered first, followed by conflict styles, where gender was treated as one control variable because of its inconsistent impact on negotiation processes (cf. Carnevale \& Lawler, 1986; Neu, Graham, \& Gilly, 1988).

As shown in Figure 2, both competing and accommodating were found positively related to negotiator's satisfaction with negotiation, but none of the five styles was related to the level of first offer, the level of assertiveness, or the level of integrativeness. When the relationships between negotiation behaviors and outcomes were examined, the level of first offer was the single factor that could predict negotiator's individual profits, whereas both the level of assertiveness and the level of integrativeness were closely related to negotiator's satisfaction with the negotiation as a whole. No relationship was found between the economic outcome--individual profit, and the affective outcome-satisfaction with negotiation, which could be an interesting topic for future studies as it might indicate that Chinese people have a relatively independent evaluation towards 
economic profit and interpersonal relationship.

\section{DISCUSSION AND CONCLUSION}

The central focus of this research was to explore Chinese conflict preferences and their impact in the process of conflict resolution. I began this study by noticing that few integrative studies had been conducted in the area of cross-cultural conflict management, and even fewer had provided actionable knowledge to the practitioners with suggestions on which style is more effective. Then using multiple sets of negotiation simulations, I investigated the conflict styles in China and examined the general impact of different conflict management styles on conflict resolving process and outcomes.

The results of this study provide strong support for the notion that collectivist Chinese tend to use non-confrontational style to resolve conflicts. Specifically, Chinese people are more likely to use compromising as a way to handle conflicts, that is, split the differences, exchange concessions, and seek a quick middle-ground position. Competing, instead of accommodating, is found to be the second preferred style in China. This is unexpected since accommodating is often referred to when talking of Chinese approach of conflict resolution, which needs further exploration as a result of this study. The results also question the relationship between conflict styles and negotiation process and outcomes in China, for which no significant impact of different conflict preferences is found in this study.

\section{Contributions}

This research extends and enriches researchers' understanding of Chinese conflict management styles in a variety of ways. First, this study confirms the notion that collectivist Chinese are more likely to use compromising to resolve conflict, which provides solid evidence for the universality of conflict management theory. Developed in an individualist culture, dual-concerned model based conflict theory proves its utility in a collectivist culture. Surprisingly, Competing is found the second preferred style in China in conflict resolution, which might reflect an either-or mentality. On the one hand, Chinese people place social relationships and social harmony above task accomplishment and personal desires (Triandis, 1995). Open and confrontational conflict is not socially sanctioned. As a result, splitting the difference and seeking a quick middle-ground position become the best way to approach any conflict in China. On the other hand, Chinese people also attach high value to face-saving, which has been studied by a 
number of scholars (e.g., Kirkbride, Tang, \& Westwood, 1991; Triandis, 1995). Consequently, when compromising position is rejected or when compromising doesn't resolve the conflict, the Chinese will feel hurt believing that their opponents not giving their face, and naturally, the power-oriented, win-lose competing style is the most effective way to fight back. Such a mentality reflects the distributive intent during conflict resolution, which may damage the long-term relationship between business partners. This result may also be related to the sample used in this study, students without professional negotiation experiences. More efforts have to be made to help them realize that the integrative, win-win solutions are possible, and the distributive or win-lose tactic is not the only method to resolve conflict.

Table 1 Means, Standard Deviations, and Correlations ${ }^{\mathrm{a}}$

\begin{tabular}{|c|c|c|c|c|c|c|c|c|c|c|c|c|c|}
\hline Variable & Mean & s. d. & 1 & 2 & 3 & 4 & 5 & 6 & 7 & 8 & 9 & 10 & 11 \\
\hline 1. Gender & 0.70 & 0.46 & & & & & & & & & & & \\
\hline 2. Competing & 6.27 & 2.45 & .05 & & & & & & & & & & \\
\hline 3. Collaborating & 5.31 & 1.94 & -.12 & $-.23 * * *$ & & & & & & & & & \\
\hline 4. Compromising & 7.11 & 2.14 & -.09 & $-.44 * * *$ & $-.24 * * *$ & & & & & & & & \\
\hline 5. Avoiding & 6.51 & 1.62 & -.05 & $-.14^{*}$ & $-.19 * *$ & $-.24 * * *$ & & & & & & & \\
\hline 6. Accommodating & 4.80 & 2.00 & $.18^{*}$ & $-.40 * * *$ & $-.28 * * *$ & -.09 & $-.16^{*}$ & & & & & & \\
\hline 7. First Offer & -.01 & 0.59 & -.07 & .07 & .02 & .02 & -.10 & -.05 & & & & & \\
\hline 8. Assertiveness Level & 5.03 & 1.06 & -.13 & -.02 & -.03 & -.06 & .07 & .07 & .01 & & & & \\
\hline $\begin{array}{l}\text { 9. Integrativeness } \\
\text { Level }\end{array}$ & 4.77 & 1.10 & .02 & .02 & -.07 & -.04 & -.02 & .12 & .03 & .12 & & & \\
\hline 10. Individual Profit & -.00 & 0.68 & .06 & .02 & .08 & -.09 & .05 & -.05 & $.15^{*}$ & .10 & .10 & & \\
\hline $\begin{array}{l}\text { 11. Satisfaction with } \\
\text { Negotiation }\end{array}$ & 4.66 & 0.92 & .04 & .07 & -.13 & -.07 & -.05 & $.16^{*}$ & .08 & $.22 * *$ & $.45^{* * *}$ & .10 & \\
\hline
\end{tabular}

a. $\quad \mathrm{N}=200$. Variables were coded as follows: gender, $0=$ female, $1=$ male; conflict style ranged from 0 to 12; Assertiveness Level: $1=$ not at all assertive, $7=$ very assertive; Integrativeness Level: $1=$ very distributive, $7=$ =very integrative; Satisfaction with Negotiation: $1=$ very dissatisfied, $7=$ =very satisfied; First Offer and Individual Profit are standardized scores.

$* \quad \mathrm{p}<0.05$ (2-tailed)

** $\quad \mathrm{p}<0.01$ (2-tailed)

$* * * \mathrm{p}<0.001$ (2-tailed) 


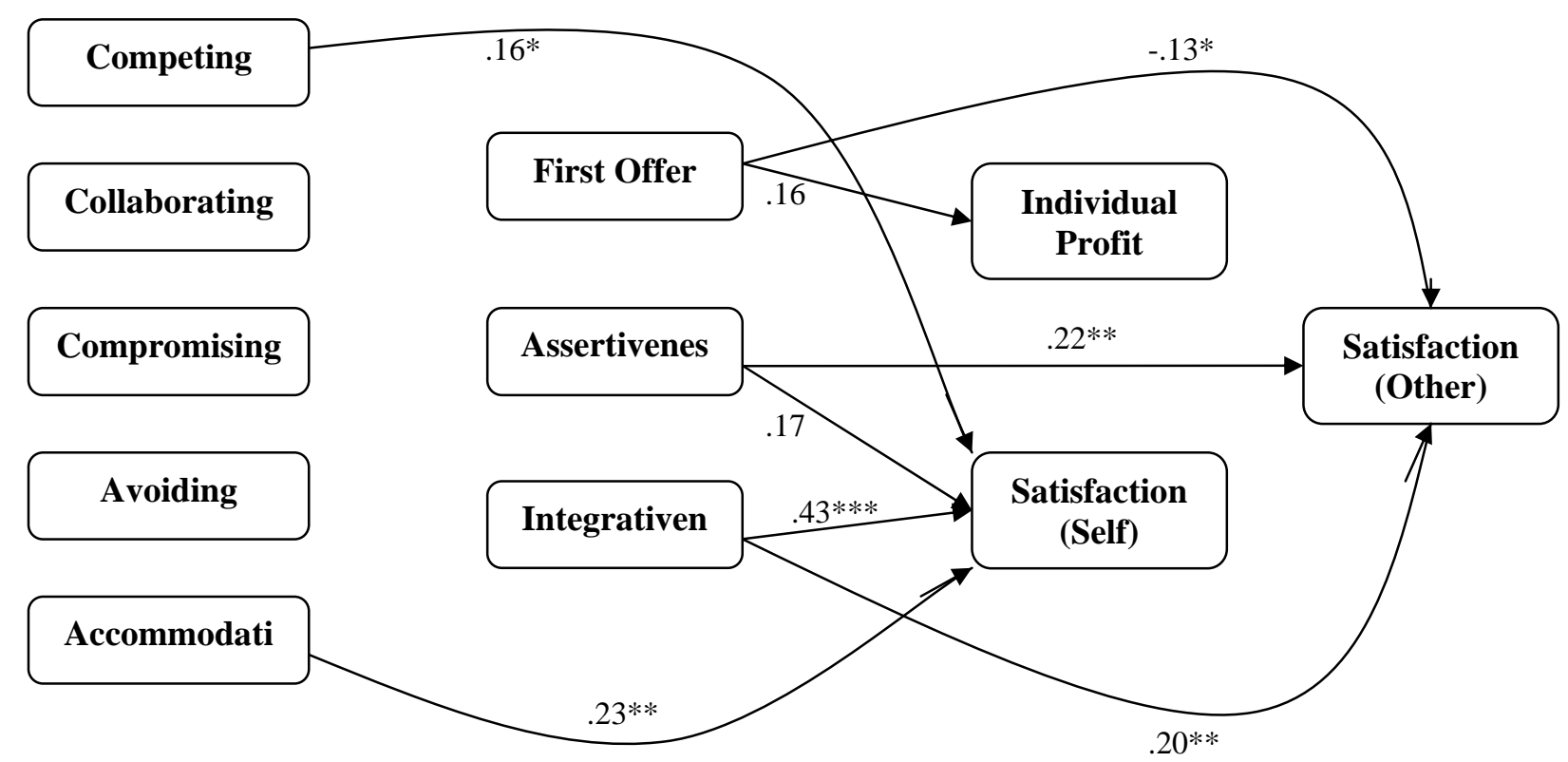

Figure 2 Results of Hierarchical Regression Analysis:

Main Effects of Conflict Styles on Negotiation Process and Outcomes ${ }^{\mathrm{a}}$

Although this study supports the validity of conflict management model in a collectivist culture like in China, no relationship is found between conflict style and conflict-resolving behaviors during business negotiations. This might suggest that either the selected behavioral criteria are not valid variables to measure negotiation process or the selected conflict management styles are not good measures for explaining negotiating behaviors. From the results in Figure 2, we can see that all the behavioral factors, the level of first offer, the level of assertiveness, and the level of integrativeness, were found significantly related to negotiation outcomes. Therefore, we incline to conclude that the measured conflict styles, based on the dual-concern model of conflict management theory, cannot predict negotiation behaviors during business negotiation in China, for which the underlying reasons will be an interesting topic for future research. Potential research issues include whether other factors such as culture influence or some situational factors suppress the impact of conflict management style.

a. Only significant relationships are presented; values along the arrows are Standardized Beta.

${ }^{*} \mathrm{p}<.05 ; * * \mathrm{p}<.01 ; * * * \mathrm{p}<.001$ 
Second, evidence about the important role that first offer plays in business negotiations also emerges from this study. The level of first offer is found to be the key process variable that predicts individual profits. This might be an important message to negotiation practitioners. As discussed previously, high first offer is a double-edged sword. Relatively extreme first offer can be favourable to the offerer as it sends a message that the party making the offer is a hard bargainer and thus the recipient of such an offer will be more likely to offer concessions, but too extreme offer will discredit the offerer to the point of breaking the negotiation. The current study supports the positive effect of an extreme first offer for obtaining the best individual results.

However, caution has to be exercised applying this finding to management practices, due to the interactive nature of business negotiations. To further explore the effect of extreme first offer, an ad-hoc test was conducted to examine the relationship between negotiator's first offer and his/her opponent's satisfaction with negotiation. The result showed that extreme first offer had significant negative relationship with the opponent's satisfaction $(\beta=-.13, \mathrm{p}<.05)$ (see Figure 2$)$. Therefore, even if extreme first offer can help negotiators achieve higher individual profits in current negotiations, it often does so at the expense of the opponents' satisfaction, which is detrimental to the long-term relationship.

Third, the relative impacts of two sets of behavioural variables also emerge from this study: the one that affects negotiator's approach to the economic outcomes during negotiations-level of first offer, and the one that affects negotiator's approach to the affective outcome-the level of assertiveness and the level of integrativeness. Our findings, as pictured in Figure 2, indicate that although higher level of first offer leads to higher individual profits, it does so with the opponent dissatisfied, as discussed above. In contrast, the second set of behaviours, the level of assertiveness and integrativeness, satisfies both the negotiator and his/her opponent. The relative emphasis on different behaviors seems to suggest that some behaviors are more important than the others for the understanding of negotiation process in China. It is worthwhile to point out here that assertiveness is not equal to aggressiveness (Yik \& Bond 1993). As assertiveness involves a freer exchange of information and persuasion and more active involvement in pushing negotiation forward, if the negotiator is doing so with an integrative intent, higher level of assertiveness will result in more cooperation and willingness to share information, which consequently satisfies both sides during negotiation. 


\section{Limitations and Future Study Directions}

This study was based on the analysis of student samples in business negotiation simulations, a characteristic that limits the generalization of the findings. The student sample might be different from the general population sample. This being said, however, one could argue that even though the student sample may not represent the general population of China, this study is still valuable for its exploratory nature in this area, and the results provide insightful directions for advanced studies in this area.

The data are not immune to the possibility of common method bias-always a concern when single-source, sing-report data are used. However, a key criterion of conflict styles, i.e., the level of assertiveness, didn't come from the focal individual, but from his or her opponent. In addition, the level of first offer and individual profit-two key dependent variables in this study, are actual numbers, not just evaluative self-reports, and they were both standardized before data analysis.

Future studies are needed to explore some of the issues not answered in this study. First, using different sample to replicate this study is a reasonable extension for this line of research. Second, if conflict styles are not the valid predictors of negotiating behaviours in China, then what are valid ones? In addition, the effect of extremeness of first offer can be examined to test what is the ultimate limit for negotiators to make their first offers, which will be very interesting for professional negotiators. Future studies can also investigate the reasons why the Chinese prefer compromising to other styles during conflict resolution and how national culture affects the impact of conflict management styles on conflict resolution process. This is a topic not dealt with in this study.

\section{REFERENCES}

Adler, N. J., \& Graham, J. L. (1989). Cross-cultural interaction: the international comparison fallacy? Journal of International Business Studies, 20, 515-537.

Barry, B., \& Friedman, R. A. (1998). Bargainer characteristics in distributive and integrative negotiation. Journal of Personality and Social Psychology, 74, 345-359.

Blake, R. R., \& Mouton, J. S. (1964). The managerial grid. Houston, TX: Gulf Publishing.

Brislin, R. W. (1986). The wording and translation of research instruments. In W. J. Lonner, \& J. W. Berry (Eds.), Field methods in cross-cultural research (pp. 137164). Newbury Park: Sage.

Calhoun, P. S., \& Smith, W. P. (1999). Integrative bargaining: Does gender make a 
difference? International Journal of Conflict Management, 10(3), 203-224.

Carnevale, P. J., \& Lawer, E. J. (1986). Time pressure and the development of integrative agreements bilateral negotiations. Journal of Conflict Resolution, 30, 636-656.

Carnevale, P. J., \& Pruitt, D. G. (1992). Negotiation and Mediation. Annual Review of Psychology, 43, 531-582.

Churchill, G., Walker, O., \& Ford, N. (1990). Sale Force Management (3rd edition). Homewood, IL: Irwin.

Cronbach, L. J. (1951). Coefficient alpha and the internal structure of tests. Psychometrika, 16, 297-334.

Greenhalgh, L., Nelsin, S. A., \& Gilkey, R. W. (1985). The effects of negotiator preferences, situational power, and negotiator personality on outcomes of business negotiations. Academy of Management Journal, 28, 9-33.

Hocker, J. L., \& Wilmot, W. W. (1991). Interpersonal Conflict. Dubuque, IA: W. C. Brown.

Hofstede, G. (1980). Culture's Consequences: International Differences in Work-Related Values. Beverly Hills, CA: Sage.

Jehn, K. A., \& Weldon, F. (1992). A comparative study of managerial attitudes toward conflict in the United States and the People's Republic of China: Issues of theory and measurement. Paper presented at the annual meeting of the Academy of Management, Las Vegas, NV.

Kiggundu, M. N., Jorgensen, J. J., \& Hafsi, T. (1983). Administrative theory and practice in developing countries: A synthesis. Administrative Science Quarterly, 28, 66-84.

Kirkbride, P. S., Tang, F. Y., \& Westwood, R. I. (1991). Chinese conflict preferences and negotiating behavior: cultural and psychological influence. Organization Studies, 12(3), 365-389.

Kozan, M. K. (1997). Culture and conflict management: A theoretical framework. International Journal of Conflict Management, 8(4), 338-360.

Lewicki, R. J., \& Litterer, J. A. (1985). Negotiation. Homewood, IL: Irwin.

Lewicki, R. J., Litterer, J. A., Minton, J. W., \& Saunders, D. M. (1994). Negotiation (2nd edition). Burr Ridge, IL: Irwin.

Ma, Z. (2006). Negotiating into China: The Impact of Individual Perception on Chinese Negotiations Styles, International Journal of Emerging Markets, 1(1), 64-83.

Ma, Z., Wang, X., Jaeger, A., Anderson, T., \& Wang, Y. (2000, July). Individual perception, bargaining behavior, and negotiation outcome: A Chinese case. 
Proceedings of the 2000 Annual Meeting, Administrative Science Association of Canada, 21(8).

Mnookin, R. H., Peppet, S. R., \& Tulumello, A. S. (1996). The tension between empathy and assertiveness. Negotiation Journal, 12(3), 217-230.

Neu, J., Graham, J. L., \& Gilly, M. C. (1988). The influence of gender on behaviors and outcomes in a retailer buyer-seller negotiation simulation. Journal of Retailing, 64, 427-451.

Rubin, J. Z., \& Brown, B. R. (1975). The Social Psychology of Bargaining and Negotiation. New York: Academic.

Ruekert, R., \& Churchill, G. (1984). Reliability and validity of alternative measures of channel member satisfaction. Journal of Marketing Research, 21, 226-233.

Siegel, S., \& Fouraker, L. E. (1960). Bargaining and group decision making: Experiments in bilateral monopoly. New York: McGraw Hill.

Sorenson, R. L., Morse, E. A., \& Savage, G. T. (1999). A test of the motivations underlying choice of conflict strategies in the dual-concern model. International Journal of Conflict Management, 10(1), 25-44.

Thomas, K. W. (1976). Conflict and conflict management. In M. Dunnette (ed.), Handbook of Industrial and Organizational Psychology (pp. 889-935). Chicago: Rand McNally.

Thomas, K. W., \& Kilmann, R. H. (1974). Thomas-Kilmann Conflict MODE Instrument. Tuxedo, NY: Xicom.

Thompson, L. (1990). Negotiation behavior and outcomes: empirical evidence and theoretical issues. Psychological Bulletin, 108, 515-532.

Tjosvold, D., Leung, K., \& Johnson, D. (2000). Cooperative and competitive conflict in China. In M. Deutsch \& P. T. Coleman (Eds.), Handbook of Conflict Resolution: Theory and Practice (pp. 475-495). San Francisco,CA: Jossey-Bass Publishers.

Triandis, H. C. (1995). Individualism and Collectivism. Boulder, CO: Westview.

Trubisky, P., Ting-Toomey, S., \& Lin, S. L. (1991). The influence of individualismcollectivism and self-monitoring on conflict styles. International Journal of Intercultural Relations, 15, 65-84.

van de Vijver, F., \& Leung, K. (1997). Methods and data analysis of comparative research. In J. W. Berry, Y. H. Poortinga, and J. Pandey (Eds.), Handbook of CrossCultural Psychology (V.1, pp. 257-300). Needham Heights, MA: Allyn \& Bacon.

van de Vliert, E. (1997). Complex interpersonal behavior: Theoretical frontiers. East 
Sussex, UK: Psychology Press.

van de Vliert, E., \& Euwema, M. C. (1994). Agreeableness and activeness as components of conflict behavior. Journal of Personality and Social Psychology, 66, 674-687.

van de Vliert, E., \& Kabanoff, B. (1990). Toward theory-based measures of conflict management. Academy of Management Journal, 33, 199-209.

Volkema, R. L., \& Bergmann, T. J. (1995). Conflict styles as indicators of behavioral patterns in interpersonal conflicts. Journal of Social Psychology, 135(1), 5-15.

Wall, J. A. (1985). Negotiation: Theory and Practice. Glenview, IL: Scott, Foresman, \& Company.

Wall, J. A., \& Blum, M. W. (1991). Negotiations. Journal of Management, 17, 273-303.

Weldon, E., \& Jehn, K. A. (1995). Examining cross-cultural differences in conflict management behavior: a strategy for future research. International Journal Conflict Management, 6, 387-403.

Womack, D. F. (1988). Assessing the Thomas-Kilmann Conflict Model Survey. Management Communication Quarterly, 1(3), 321-349.

Yik, M. M., \& Bond, M. H. (1993). Exploring the dimensions of Chinese person perception with indigenous and imported constructs: Creating a culturally balanced scale. International Journal of Psychology, 28(1), 75-95. 